\title{
Excombatientes y procesos de paz en Colombia: Una mirada a la democracia en tiempos de posacuerdo*
}

\author{
Former combatants and peace processes \\ in Colombia: \\ A look at democracy in times of post-agreement
}

\author{
Valentina Pulido Valenzuela* \\ Daniela Rodríguez Castillo** \\ David Ruiz Estepa ${ }^{* * *}$
}

\section{RESUMEN:}

En tiempos de posacuerdo corresponde a todos, como actores de la sociedad, reconocer la carga simbólica, política e ideológica del conflicto armado interno que ha existido por más de 70 años $^{1}$ en el territorio colombiano.

Artículo de Revisión.

** Estudiante de Ciencia Política de la Universidad de San Buenaventura, sede Bogotá. Correo Institucional: Lvpulidov@academia.usbbog.edu.com

*** Estudiante de Derecho de la Universidad de San Buenaventura, sede Bogotá. Correo Institucional: drodriguezc1@academia.usbbog.edu.com

**** Estudiante de Derecho de la Universidad de San Buenaventura, sede Bogotá. Correo Institucional: dsruize@academia.usbbog.edu.com

1 El origen de las guerrillas liberales y los gobiernos conservadores que cooptaron el poder político. 
Es preciso decir que la paz es el resultado de continuos procesos; por consiguiente, para que pueda ser posible avanzar es necesario romper con los círculos interminables de violencia que genera la exclusión política, otorgando reconocimientos a las partes del conflicto y permitiendo consensos, no con prácticas represivas y violentas, sino democráticas y representativas (Jaramillo, 2014)-

Bajo esta reflexión, el presente artículo tiene como objetivo resaltar la importancia de fomentar espacios para los liderazgos políticos que puedan asumir los excombatientes en los territorios, haciendo conciencia de lo que significa el liderazgo más allá de un número reducido de curules en el congreso de la república ${ }^{2}$. Estudiamos también la necesidad de generar una cultura política en la sociedad y los retos en los que se ven inmersos los excombatientes al querer ser parte del escenario político y la vulnerabilidad en que se ejercen los liderazgos en Colombia.

Enfatizando en la importancia de reconocer al excombatiente no como un enemigo, sino como un líder opositor que lleva consigo nuevos proyectos e ideales políticos.

\section{Palabras claves:}

Excombatientes, posconflicto, democracia, liderazgo, política, sociedad, opositor, enemigo, garantías, representatividad, violencia, exclusión.

\section{Abstract:}

In post-agreement times, it is up to everyone, as actors in society, to recognize the symbolic, political and ideological burden of the

2 Curules para las FARC 2018 y 2022. Véase también:https://www.semana.com/nacion/articulo/ proceso-de-paz-estas-serian-las-curules-de-las-farc-en-el-congreso/491068/ 
internal armed conflict that has sparked for more than 70 years in Colombian territory.

Peace is only the result of continuous processes; however, in order for us to move forward, it is necessary to break with those endless circles of violence by granting recognition to the parties to the conflict, allowing a consensus, not with repressive and violent practices, but rather democratic and representative ones.

Under this reflection, this article aims to highlight the importance of fostering spaces for political leadership that excombatants can assume in the territories, raising awareness of what leadership means beyond a reduced number of seats in the Congress of the Republic. We also study the need to generate a political culture in society and the challenges that ex-combatants are immersed in when they want to be part of the political scene, the vulnerability in which leaderships are exercised in Colombia.

Emphasizing the importance of recognizing the former combatant, not as an enemy but as an opposition leader who carries with him new projects and political ideals.

\section{Keywords:}

Former combatants, post-conflict, democracy, leadership, politics, society, opponent, enemy, guarantees, representativeness, violence, exclusion.

\section{Introducción:}

En un Estado Social de Derecho, la participación política representa la piedra angular de la democracia, pues a través de este mecanismo los ciudadanos, no solo forman, construyen e inciden en las decisiones políticas del Estado, sino que, además, tienen la posibilidad de acceder al poder político. (Córdova y Vela, 2017, p. 8) 
Sin embargo, en Colombia, a lo largo de su historia, el derecho al ejercicio político fue negado y limitado por parte de las élites representadas y consolidadas en los partidos tradicionales. Más allá del espectro político conformado por estos extremos no era posible imaginar nuevas ideologías, posiciones o visiones para la democracia nacional.

Particularmente, esta investigación aborda un tema actual y vigente que representa la realidad del país, que vincula a los ciudadanos activos de la democracia, pues este delicado tema va más allá de los sentimientos de la sociedad y de todas las víctimas; debe ser observado y estudiado de manera objetiva, para que sea posible reflexionar sobre la importancia de asegurar y permitir la participación política y el ejercicio a la oposición a una comunidad de excombatientes con origen en una guerrilla desmovilizada.

Esta posibilidad de abrirles espacios de participación a los excombatientes para que puedan brindar sus discursos de una forma pacífica tiene un alto nivel representativo, entendiéndose que la paz se construye y consolida por medio de una legítima representación, mas no por medio del uso de un fusil, utilizando símbolos pacíficos y democráticos, donde exista una posibilidad real para cualquier nuevo interlocutor con fines distintos a los tradicionales.

Bajo dicho panorama, el presente trabajo comprende cuatro partes: en la primera de ellas se hace un análisis sobre el reconocimiento de los disidentes como actores políticos bajo un entorno democrático que se encuentra sustentada en bases como la opinión pública, la falta de garantías y el incumplimiento a diferentes acuerdos consolidados en los diálogos de paz, (Monzón, C. 2006).

El artículo procede con la segunda parte de la investigación, en donde se inquiere sobre la desprotección estatal para los excombatientes en el marco de un posacuerdo, junto con el análisis a los 
diferentes elementos que ocasionan barreras y dificultades para el ejercicio político, democrático y participativo de esta comunidad. Seguido a esto se encuentra la tercera parte, enfocada al importante papel que tiene la opinión pública en la búsqueda de participación política y apertura democrática para construir paz.

Por último, se llevará a cabo un análisis de las estructuras de poder y el acceso a los espacios participativos y de oposición por parte de estos nuevos líderes políticos al espacio civil, político y público.

Así entonces, este trabajo hace una invitación y reflexión para que se tome con especial responsabilidad y gran atención la participación política para estos nuevos interlocutores ideológicos, que serán los excombatientes, para que de manera consecuente se convierta en una realidad la construcción y consolidación de la paz, la verdad, el perdón y la reconciliación luego de que tantas generaciones vivieran la guerra, y que, finalmente, cada persona logre hacer un aporte real para dar el fin permanente de un histórico conflicto.

\section{Desprotección estatal para los excombatientes en tiempos de posacuerdo}

La mirada de las disidencias es una de las más cruentas visiones a lo largo de la línea del tiempo en los procesos para la paz, en donde se identifica un factor común, la desprotección total o parcial de los excombatientes. Lo anterior provoca métodos de destrucción de los liderazgos sociales, que van desde la cooptación, la criminalización, la persecución, la intimidación y el desplazamiento hasta la eliminación física de quienes logran niveles de reconocimiento y representatividad en contextos sociales y territoriales donde predominan los intereses de grupos minoritarios de poder (Caro, A. 2020), que ha puesto en constante riesgo el respeto a los valores democráticos. 
El segundo punto del Acuerdo Final Para la Terminación del Conflicto (2016), referente a la garantía con rango de ley que otorgó el Estado Colombiano, asegura el ejercicio de la participación política de todo líder que pretenda acceder a esos espacios de deliberación democrática. Para tal fin concibe la creación de un Sistema Integral de Seguridad para el Ejercicio de la Política ${ }^{3}$, se trata de un esquema de protección y articulación de las instituciones del orden nacional, departamental y municipal que sirvieran como un espacio de interlocución y seguimiento a las condiciones de seguridad y protección de los integrantes de los partidos y movimientos políticos, aquellos quienes especialmente ejercieran la oposición, como los defensores de derechos humanos y el nuevo movimiento surgido del tránsito de las FARC-EP a la actividad política legal y de sus integrantes en proceso de reincorporación a la vida civil.

Por otra parte, es necesario mencionar que estos espacios de interlocución institucional que prevén eventualmente alertas tempranas, evaluaciones y seguimiento que protegen a los excombatientes que son ahora actores políticos (Acuerdo Final para la paz, 2017), muestran un serio déficit de efectividad, pues la vulnerabilidad en que se ejercen los liderazgos es todavía una de las serias fracturas para una paz estable.

Según los informes trimestrales de la misión de verificación de la ONU (2002) ${ }^{4}$, se registra, desde los acuerdos de paz firmados en la Habana, 237 excombatientes asesinados, 55 tentativas de homicidio y 21 desapariciones forzadas de exintegrantes de las FARC, el 27.7 \% cerca de las áreas de reincorporación, entre ellos líderes políticos de menor y mayor rango.

3 Expedición del Decreto 895 de 2017 otorga garantías y condiciones para el ejercicio político, teniendo como principal objetivo la creación de programas, acciones y medidas para la protección integral de líderes en los territorios que pretendan generar liderazgos.

4 Véase, Misión de Verificación de las Naciones Unidas en Colombia Informe del Secretario General S/2020/943 
Todo responde a las líneas de mando y poder que se establecen dentro de los acuerdos, en donde se concertan los intereses de los firmantes como un eventual resultado de reestructuraciones económicas, remuneraciones, procesos de indulto y hasta curules con circunscripción especial en lo más alto de la legislación política.

Sin embargo, todo el análisis se reduciría a una mirada limitada de los procesos en el marco de la democracia si no se trabaja en las problemáticas de fondo; nos referimos a la participación de los excombatientes en los espacios de diálogo político, y la inseguridad física e integral a la que están expuestos, sobre todo los de bajo rango que quieran participar y ser voceros, es decir, aquellos líderes convertidos en voceros dentro de sus territorios y que se encuentran desprotegidos ante la medida de acción institucional, (Vergara, J. Prada, T. Aparicio, A. y Martínez, L. 2019).

Dejando atrás el seguimiento consultivo de estas instituciones y estrategias de acompañamiento para asegurar la protección a los líderes excombatientes, pasamos al plano de acción, en donde la Jurisdicción Especial para La Paz instauró medidas cautelares de protección colectiva hacia la UNP (Unidad Nacional de Protección), ordenando la estructuración de un esquemas de protección, además de la realización de los estudios de riesgos pendientes y el fortalecimiento de la Mesa Técnica de Seguridad y Protección ${ }^{5}$, que se encargan específicamente de la protección de estos líderes excombatientes de las FARC; no obstante, aún se denotan problemas presupuestales y de organización para asegurar tal garantía.

En base al anterior análisis, no se puede esperar una eventual continuación de los procesos para la paz, después de los dos cuatrienios

5 Las principales funciones de esta Mesa Técnica son desarrollar la estructura de la Subdirección Especializada de Seguridad y Protección de la UNP e identificar las necesidades en materia de recursos humanos, físicos y de presupuesto requeridos para la implementación del Plan Estratégico de Seguridad y Protección para los líderes excombatientes que decidan tomar el camino democrático (Unidad Nacional de Protección, 2018). 
de las que gozan las curules especiales para los excombatientes, si no se rompe con el círculo sin fin de violencia, en donde se les limita a la protección institucional del Estado y hacen de estos espacios riesgosos para los líderes que podrían cambiar con el panorama nacional.

\section{El reconocimiento de los disidentes como actores políticos en un entorno de democracia cambiante}

A diferencia de los anteriores balances que en particular relacionan la política opositora de los excombatientes con el terrorismo, actos barbáricos, narcotráfico, violencia y resiliencia por parte de las FARC-EP, se pretende hacer visible la otra cara de aquellos quienes tomaron el camino de las armas, luchando bajo múltiples simbolismos encaminados a diferentes ideologías revolucionarias que tendrían como fin último conseguir una mayor representación política.

Aquella a la que se refirió Saumeth (2010), como el efecto de una violencia política que desde el principio pretendió convertirse en acción revolucionaria, en donde primó el esfuerzo y la decisión política de iniciar procesos de construcción con una fuerza armada para combatir al Estado para combatirlo, haciendo de esta una respuesta militar a la acción del Estado por la defensa del territorio. Este es el inicio del conflicto y por supuesto opera para identificar el perfil político de un combatiente de aquellos, quienes se quiera o no, en tiempo de posconflicto, son portadores de nuevos proyectos políticos.

El más grande de los retos de los excombatientes para encontrar la paz en Colombia es el de recordar las aspiraciones políticas, entendiendo entonces sus exigencias de negociación para adoptar, en la discusión de la agenda, temas como los derechos civiles y políticos 
para que las FARC-EP se consolidarán como una fuerza política de oposición legítima (Córdoba y Vela, 2017, p. 59).

De manera que los múltiples intentos fallidos por construir la paz han generado una desconfianza negociadora entre las partes firmantes, pues aún no se ha terminado de reconocer que el fin de la guerra no se dará por vencedor militarmente, ni a largo o mediano plazo.

Al respecto, la comisión de Personalidades de la mesa de diálogos (2001) hace una reflexión:

La experiencia histórica, tanto en Colombia como en el mundo, demuestra que en el esquema de la negociación bajo el fuego no produce resultados satisfactorios (...) en el objetivo de mantener la paz. Porque, entre otras cosas, supone mantener la aspiración de cada una de las partes en conflicto de imponerse por la fuerza de las armas a la parte contraria, hasta derrotarla militarmente.

En particular, el acuerdo firmado en la Habana, Cuba, supuso un paso enorme en la búsqueda de la paz, en donde se entiende que para negociar es necesario reconocer bajo la lógica del simbolismo que representaba cada ataque contra el Estado. La carga simbólica de todos los actos de la guerrilla se ceñía a mensajes de rebelión y connotaciones políticas. Por esa razón no es correcto categorizar todos los actos de las FARC-EP como actos de terrorismo ni, particularmente, a ellos mismos como terroristas, por lo que se debe entender el conflicto como uno menos globalizado, para lograr planes que conduzcan a una ruta negociadora más efectiva. De no ser así, cambiaría totalmente el panorama político del conflicto en el territorio colombiano, las rutas de trasformación a visiones futuras de las fuerzas opositoras y la posibilidad de cambio, en donde un disidente se sienta convencido de que las condiciones de exclusión política han cambiado. 
Córdoba y Vela (2017) añaden, conforme a lo expuesto, que no es viable que en tiempos de consensos y de reconstrucción a la democracia (historias, víctimas y victimarios) que se reduzca la lucha de la guerrilla al actuar de un grupo terrorista, porque esta connotación impide buscar nuevas salidas negociadas con los retos futuros a los que pueda ser sometida la paz y la negociación. La razón es porque no se reconoce al excombatiente como un actor político, sino como un terrorista; es decir, se reconoce al adversario no como un opositor, sino como un sujeto que atenta contra la tranquilidad de la ciudadanía, convirtiéndose en el enemigo.

Similar a esta idea es la teoría de homogeneización del otro, basada en la relación "amigo-enemigo" tomada de Arendt, H. (1958) y desarrollada por Madrigal, L. (2010); explica que el fenómeno que tiene la sociedad colombiana con los excombatientes, en relación con la exclusión política y social, creando un entorno conflictivo, se fundamenta en principios, valores, ideologías o creencias absolutos, en donde se rechazan los pensamientos diferentes a los establecidos, creando un imaginario de homogeneización de la sociedad, lo que produce un rechazo a la solidaridad con la diferencia.

Asimismo, se deslegitima toda posibilidad de nuevos proyectos políticos por parte de los disidentes que quieran ser líderes políticos, capaces de liderar espacios de conversación en comunicación directa con el Estado, así como con los mismos ciudadanos en el territorio, más allá de resolver su posición de disidente, sino a convertirse en un vocero que aporte en la conducción para terminar con el conflicto, la evidente desigualdad e injusticia en el país.

Esta resulta como la única manera para trazar una hoja de ruta en tiempos de post conflicto, considerando que la firma de un eventual acuerdo no solo prevé la resolución de una democracia estática, (Sartori, 2012)., sino que se rige en una dinámica de constante 
cambio y de manera consecuente de constantes nuevos retos para conseguir una paz estable.

Por otro lado, resulta más provechoso para un gobierno abrir espacios de comunicación recíproca, que prevengan nuevas disidencias de los grupos guerrilleros que busquen las armas para ser escuchados, rompiendo con la típica visión del Estado como un ente distante e indiferente, emergiendo como un símbolo del reconocimiento moral y político del "enemigo" alzado en armas, quien, pese a haber cometido graves conductas criminales en el marco del conflicto armado, mantiene una dignidad moral, justificación suficiente para que el gobierno pueda convocar a una negociación política, (Sentencia c- 571. 2019)

La idea de estudiar estos poderes políticos deviene de esa naturaleza altamente excluyente de las estructuras y dinámicas para el consenso político en tiempos de conflicto y posconflicto, en tanto que resulte fundamental abrir y garantizar un espacio democrático para el ejercicio de la oposición (Pécaut ,D. 2005).

Se debe plantear una apertura de manera constante a las mesas de conversación con los grupos que busquen establecer la paz, no solo en el momento en que se estén firmando los procesos, pues una conversación continuada permite llevar un seguimiento juicioso del proceso, una rendición de cuentas para las instituciones creadas para orientar a los líderes excombatientes para que puedan tener mayor efectividad.

Reconociendo que en el ambiente político se vive con diferentes posiciones, ideas y situaciones, es esencial tener un acompañamiento institucional que genere mayor legitimidad y credibilidad en las garantías de no repetición, para, así, llegar a formar un semillero de verdaderos líderes políticos en los territorios. 
El éxito para logra la participación política de las FARC-EP, que es una exigencia de esta organización, depende de un apoyo continuo, estableciendo, más allá de su derecho a ser elegidos, el interés de la sociedad por reforzar la democracia.

\section{Acceso al poder político para los excombatientes y la opinión pública bajo la teoría "espiral del silencio" de Noelle-Neumann}

La sociedad civil y medios de comunicación desempeñan un papel preponderante en los acuerdos, y no única y exclusivamente antes de su desarrollo, sino especialmente durante su implementación desde su firma en la Habana, en el año 2016. El éxito de los acuerdos de paz depende en gran medida de la opinión pública, construida por los ciudadanos. Es por esto que el posacuerdo no solo significa un logro, sino también un verdadero reto, en donde la eficacia de la opinión pública puede llegar a construir una cultura de paz, perdón y reconciliación. (Turriago, 2016).

Para Noelle-Neumann (1995) existe un modelo que explica la influencia de la opinión pública sobre los individuos, y parten desde sus opiniones y acciones, a lo cual denomina "la espiral del silencio", en donde analiza el peligro del aislamiento que significa expresar la opinión contraria, o actuar en público de acuerdo a ella. En otras palabras, se puede describir a la opinión pública como la opinión dominante que obliga a la obediencia de actitud y comportamiento, amenazando al individuo disidente con el aislamiento y al político con la pérdida del apoyo popular.

Bajo esta teoría se logra explicar cómo la opinión pública está constituida por aquellas opiniones sobre temas controvertidos que pueden expresarse en público, haciendo que algunos individuos, en este caso nuestro sujeto de reflexión, el excombatiente, permanezcan 
deliberadamente en silencio porque pueden percibir que sus opiniones contradicen a las de la mayoría o pueden creer que expresarse en público o frente a otros individuos les podría significar algún tipo de crítica. De esta forma es, entonces, que esta minoría silenciosa entraría poco a poco en una especie de espiral, mejor llamada por Neumann como la espiral del silencio, de modo que el punto de vista disidente, diferente o contrario irá paulatinamente desapareciendo de la escena, al quedar enmudecidos por la opinión pública (Anto, R. 2018)

Resultados totalmente sorpresivos, como la victoria del "No" en el plebiscito convocado por el gobierno de Juan Manuel Santos (2016) para el acuerdo de paz, se convierten en perfectos escenarios que ejemplifican la teoría de Neumann, ya que la gran mayoría de observadores nacionales consideraban el voto del "Sí" por la paz como un logro asegurado ${ }^{6}$. Basado en lo anterior, es incorrecto pensar que el ejercicio político se basará en todo momento en lo políticamente correcto, porque las opiniones reales están inmersas en diferentes diálogos, ideas y posiciones que dejó la guerra y el dolor, y que crean un imaginario en donde el excombatiente no merece estar en los espacios del disenso político, porque para la sociedad son caminos trazados con secuestros, asesinatos y narcotráfico; eso Colombia no lo ha olvidado. (Boris, M. 2016). 6424385 colombianos demostraron ser la excepción a la regla por apoyar lo "políticamente correcto" y lo "socialmente aceptado", (Redacción El Tiempo. 2016).

Es por esto por lo que el fenómeno de "la espiral del silencio" es, entonces, una de las grandes barreras que tiene la reconciliación, la segura reintegración, el perdón y, en especial, la posibilidad del ejercicio político y participativo en la democracia por parte de esta comunidad de excombatientes. Lo público, lo social y la ciudadanía

6 La opinión pública se puede identificar por medio del resultado que se tuvo en la sociedad a lo largo de los diálogos y acuerdos de paz, recordando cómo "Con un 50,2\% de los votos válidos a favor del NO, los colombianos rechazaron el 2 de octubre de 2016 por vía del plebiscito los Acuerdos de Paz que el Gobierno había negociado con las Fuerzas Armadas Revolucionarias de Colombia (FARC)" (Basset, 2018, p. 243). 
tienen posiciones en las que no se sienten interpretadas ni motivadas por el discurso de la paz, y en realidad poseen imaginarios sociales que muestran un temor por la llegada de estos individuos a diferentes espacios públicos y de poder. ¿Cómo se puede romper y terminar con la espiral del silencio en la que se encuentra la sociedad colombiana? Siguiendo las ideas del núcleo duro de Noelle-Neumann (1995):

La minoría que queda al final de un proceso de espiral del silencio desafiando la amenaza de aislamiento (...) Un núcleo duro puede dar la espalda al público, puede encerrarse completamente cuando se encuentra en público con desconocidos, se puede encapsular como una secta y orientarse hacia el pasado o hacia el futuro más lejano. (p. 150)

Por consiguiente, es necesario que los excombatientes manifiesten públicamente sus puntos de vista y, asimismo, se unifiquen para poder formar nuevos votantes, hasta crear condiciones que posibiliten el fracaso y la caída de las posiciones, ideas y estereotipos mayoritarias que den inicio a la instalación de ideas paulatinamente nuevas que se conviertan en la opinión de las mayorías, (Anderson, J. 2016).

Por otro lado, se debe garantizar, en tiempos de posacuerdos, que la sociedad civil respalde el proceso, se informe verazmente y comprenda las causas reales del conflicto para que, de esta forma, la democracia nacional pueda ser comprendida como un verdadero espacio libre y seguro para el ejercicio político, de oposición y de opinión.

Cuando, finalmente, la opinión pública deje de ser "políticamente correcta" y sea "realmente comprendida", será el momento en que los ciudadanos, las víctimas y todos los colombianos puedan ver de forma diferente a estos excombatientes, ya no como un peligro, sino como sujetos que hacen parte de las metas para lograr construir la reconciliación y la justa participación política y democrática. 
En la medida en que se garantice una apertura democrática para los excombatientes, se dará un gran paso al cumplimiento de uno de los fragmentos más importantes para un Estado social de derecho 7 , el de la primacía del poder político y la soberanía de la sociedad en los territorios.

\section{Estructuras de poder y acceso a los espacios participativos}

El reconocimiento político es un espacio en disputa, en donde existen estrategias, alianzas, juegos políticos y formas del poder legítimo, (John, R. y Raven Bertram. 1992) ${ }^{8}$. El quehacer político significa un contexto muy diferente al acostumbrado por los excombatientes, como lo pueden ser los procesos sectoriales de las agendas políticas que refieren a alianzas, nuevos proyectos afines a sus ideologías, su imagen y la reputación. La política es una ciencia que el excombatiente debe empezar a comprender, para no solo representar a la minoría desmovilizada de las FARC, sino la nueva representación a la Colombia profunda.

Los programas de atención en tiempos de posconflicto se direccionan a tipos de atención psicológica y económica, sin permitirse conocer la carga política e ideológica del conflicto 9 , y muy a pesar de los esfuerzos por crear garantías completas que generarán una paz estable; por tanto, se exalta la necesidad de ver más allá de lo concertado, una mirada a lo que significa en un futuro el actuar político, una mirada a la protección y seguimiento institucional para los ex-

7 Refiere a un Estado democrático, participativo, pluralista, fundado en el respeto y en la dignidad humana, en el trabajo, la solidaridad de las personas y la prevalencia del interés

8 Poder legítimo basados en la teoría que divide el poder de cinco formas separadas y distintas. El poder legítimo proviene de un puesto de autoridad elegido, seleccionado o designado y puede estar respaldado por normas sociales. Este poder significa la capacidad de administrar a otros ciertos sentimientos de obligación o la noción de responsabilidad. Desarrollo y aplicación de nuevas escalas para medir las bases del poder social

9 Programas como ECOMUN que son emprendimientos para la sociedad civil y excombatiente en territorio en conflicto 
combatientes, que generen nuevos contextos que resulten en nuevas divergencias políticas, reconocidas por los líderes excombatientes.

En particular, es necesario que asuman posturas críticas y analíticas sin inmiscuir en su ideal democrático que principalmente, en tiempos de combate, aceptaban como posturas revolucionarias del prototipo político, luchando por evolucionar las políticas clasistas (Martines, M. 2006), que, a diferencia de tiempos pasados, busquen tomar el poder desde los espacios del disenso político, como los debates, argumentando las convicciones en el marco del posacuerdo, para que sea posible dar continuación a la lucha (Hobsbawm, E. 2015); esta vez no alzados en armas, sino en la búsqueda por los ideales políticos.

En primer lugar, es necesario que, en el marco del posacuerdo, se garantice una democracia real, en donde estos partidos que surjan de la nueva generación de líderes excombatientes tengan una posibilidad real de avanzar y poder consolidarse como una verdadera fuerza política en espacios directos a la legalización.

El eventual olvido, al que se refiere Fisas (2010), refiere a un modelo muy frecuente de los procesos de paz"10, "Reparto del poder político y económico", que parecerá un riesgo si no se implementan con la detallada y necesaria vigilancia, si es que el poder va a ser repartido entre las parte combatientes, debido a que la entrega de libertades y garantías solo se verían representadas en los líderes que se sentaron a firmar, mientras que los otros excombatientes del común, que tengan aspiraciones políticas, quedan en el olvido.

De ahí que surjan ciertas contradicciones al discurso democrático, al proponer la inclusión política si no se considera a la democracia como la fuerza del territorio entero. Es preciso resaltar el deber y la

10 Enfatizando en un escenario donde las exigencias de los firmantes persiguen la obtención del poder. 
necesidad de crear medidas de confianza bilaterales (Fisas, 2010), en donde se fomente la cooperación para hacer resurgir los espacios de diálogo, suprimir la ilegalidad y la represión, con el fin de construir disensos no solo en lo más alto del poder público, sino dentro del territorio, enlazar la comunicación y el apoyo, dejando de lado la visión de la opinión opositora y el quehacer político como teorías diferentes; de esta forma se erige el camino del debate y el disenso político como una verdadera alternativa popular del poder (Verdú, 2017).

\section{Generación de cultura política para la paz}

“(...) puesto que las guerras nacen en la mente de los hombres, es en la mente de los hombres donde deben erigirse los baluartes de la paz” (UNESCO, 1945)

Bajo esta reflexión se da continuación al análisis de la paz como el fruto del esfuerzo de la sociedad en su conjunto, para lograr romper el vínculo entre la política y las armas. Para tal fin se debe garantizar que todos en sociedad puedan ser capaces de expresar sus ideas políticas y garantizar el ejercicio libre de la democracia.

Cuando se piensa en una reconciliación integral es necesario considerar las reivindicaciones de la dignidad en todas sus fases en especial el de reconocerse y ser reconocido en la sociedad como un líder político. En síntesis, esto constituye la guía más importante que tiene un Estado para la construcción de una sociedad justa (Rueda, 2015).

Parte de esa construcción está en el reivindicar los discursos de todos, como actores en la sociedad, el poder considerar al otro como capaz de decidir, liderar y ser dueño de su propia autonomía. Todo esto con el fin de hacer parte del ejercicio del contrapoder y lograr ceñirse al ejercicio del discurso de lo aceptable, lo válido o lo pensable (Forst, 2014, p. 103). 
La cultura política responde a un amplio espectro de definiciones; sin embargo, todas responden a una dinámica de transición de la violencia entre "Estado y guerrilla" a un contexto de "posacuerdo" por eso el discurso político se adecuará a las diversas esferas de acción social, como la educación, la salud, el terrorismo, que definen nuevos problemas cuya descripción y posibilidades de solución atienden a esas nuevas particularidades propias para la construcción de la paz

Ahora bien, si respondemos a un contexto de autonomía democrática, como parte de un principio para conseguir una paz estable es necesario, reivindicar el derecho a redescubrir los problemas y orientar las soluciones de acuerdo con justificaciones que los propios afectados puedan considerar; eso no significa dejar de obedecer a la norma y al proceso si no la determinación del liderazgo interno en el territorio

Todo esto invita al excombatiente a seguir por el camino de una democracia participativa, porque no basta con las operaciones de ingeniería política, cuando se busca la identificación plena entre el desarrollo humano y la consolidación democrática. Lo que generaría una nueva cultura, una rendición a la violencia, una nueva generación de conciencia sobre el imaginario de una democracia consolidada que puede llegar a ser más estable que cualquier régimen de subversión para la consigna del poder político, sin olvidar que el conflicto, desde sus inicios, no hubiera sido posible sin la negación de los principios democráticos de la dignidad, la igualdad y el respeto mutuo de los hombres, y sin la voluntad de sustituir tales principios, explotando los prejuicios y la ignorancia por el dogma de la desigualdad de los hombres y de los territorios (UNESCO, 1945).

Construir generaciones con moral y cultura para el respeto y reconocimiento de los liderazgos políticos en los territorios propicia 
el reconocimiento de las ideas, el debate y el consenso, que aumenten las posibilidades de la toma de decisiones de manera más justa y con visiones más pluralistas, que incidirían en la gobernabilidad ${ }^{11}$ de los líderes presentes y futuros.

Parte de esta idea proviene de Nordquist (2007), que invita a cambiar el entendimiento y las formas no violentas para la resolución de conflictos.

En aras de la cooperación, es necesario transformar la manera como las personas en el territorio, que en el pasado fueron víctimas del conflicto, resuelven los problemas derivados de la interacción personal, y la solución más próxima sea la interlocución de las ideas (Méndez y Casas, 2009). Se debe hacer énfasis en la posibilidad de analizar a niveles micro la manera como los individuos se integran en un sistema político porque esto permitiría abrir nuevas perspectivas de investigación que complementen las visiones canonizadas de los disidentes (Uraguiza, 2013).

Para estos procesos es necesario concientizar a los excombatientes y a la sociedad misma del empoderamiento político que pueden tener, representando el ejercicio altamente ideológico de asumir una posición política; sensibilizar al disidente del poder político que tiene como ciudadano. Incentivar el liderazgo político significa dejar atrás las consecuencias de la exclusión política para el excombatiente promedio que no representa una cara conocida del conflicto, que no está preparado, según la sociedad, para los ideales deliberativos que requieren los espacios del poder político.

Bajo sus avances conceptuales y avances empíricos, Juan Esteban Uraguiza (2013) retoma datos del proyecto "Deliberaciones en 
sociedades divididas"12, que corresponde a la aplicación del instrumento $\mathrm{DQI}^{13}$, se transcribieron algunas de las discusiones de los excombatientes para poder codificar bajo cinco componentes de deliberación, entre ellos: argumentación, búsqueda del bien común, disposición de ceder bajo el mejor argumento, entre otros, con el fin de evaluar aptitudes y determinar la calidad democrática. Consecuentemente, los resultados fueron entre otros que la deliberación de los excombatientes es posible, incluso, entre quienes han hecho uso de la violencia como mecanismo de salvaguardar sus diferencias (...) los excombatientes de grupos de guerrillas y paramilitares presentan de manera espontánea niveles de participación y argumentación cercanos al ideal deliberativo.

Bajo estos resultados, se resalta la capacidad de liderazgo en los espacios de deliberación política para aquellos que dejaron las armas y en las mesas de conversación política; sin embargo, es posible que el excombatiente no cuente con la preparación y el conocimiento para ser un correcto líder en el territorio, aunque cumpla con todos los requerimientos en su discurso. Es por esto que es necesario fortalecer la asesoría institucional que corresponda, de esta manera se permitiría reconstruir un nuevo horizonte, así como generar nuevas representaciones entre individuos, grupos o sociedades, ampliando la visión de los actores del conflicto del presente para pensar en los nuevos líderes del futuro.

12 El proyecto deliberaciones en sociedades divididas ofrece el conjunto de criterios más coherente para medir la calidad del comportamiento político. Esta teoría asume que la discusión política en condiciones de participación libre e igual, respeto, intercambio de argumentos, búsqueda del bien común y disposición a ceder ante los mejores argumentos, impregna de validez y legitimidad las decisiones y posiciones resultantes (Uraguiza, 2013)

13 DIQ (Discourse Quality Index) es actualmente el estándar evaluativo más usado en el mundo para medir los niveles de deliberación, e incluye indicadores de participación, respeto, justificación, búsqueda del bien común y fuerza del mejor argumento (Uraguiza 2013). 


\section{Conclusiones}

Para lograr conseguir una verdadera paz estable es necesario analizar los círculos interminables de violencia que parecen repetirse a lo largo de los procesos y mesas de consensos para la paz. Es así como en este artículo se estableció la necesidad de romper con el esquema del enemigo y el Estado benefactor, es decir, dejar atrás autoproclamadas posiciones del vencedor y perdedor. Estos tiempos de posacuerdo no son fruto del triunfo de ninguna de las partes y por eso es menester reconocer las aspiraciones políticas que tienen los excombatientes, que en principio pretendían convertirse en acciones políticas y revolucionarias.

Si esto no es tomado en cuenta, realmente no se está cortando con la verdadera raíz del conflicto; lo que sí se está haciendo es resolviendo los intereses más próximos de los firmantes, dejando a los demás excombatientes en el olvido, lo que genera una contradicción al discurso democrático de la paz.

Se trata de fortalecer integralmente el proceso para la paz que, al contrario de lo que se piensa comúnmente, también significa darle una nueva voz a los excombatientes; todos en la sociedad, sin excepción, deben ser capaces de expresar sus ideas políticas y poder ser parte de la hoja de ruta para hacer de esta una paz estable y duradera, en donde ,finalmente, pueda ser posible hablar del libre ejercicio de la democracia y construir verdadero semilleros de líderes políticos que permitan una contraposición en la toma de decisiones en los territorios.

La falta de incentivos para invitar a los excombatientes a ser líderes políticos en el territorio se refleja en uno de los mayores retos para estos, y esta es la situación de vulnerabilidad en la que se ejercen los liderazgos, (Arias, R. 2015). Esta situación les ocasiona temor de ser las caras visibles que representan el territorio porque no cuentan 
con un apoyo institucional real, que resulta como un factor de riesgo continuo si no presentan garantías de protección y seguimiento para estos líderes políticos, consecuentemente, no es posible concebir una generación que prefiera el debate y el discurso antes que la violencia si no se garantizan estos espacios seguros y protegidos.

Parte de esa violencia no se direcciona solo a las armas, sino también a los esquemas altamente excluyentes que genera la sociedad al considerar al actuar guerrillero como terrorista, encasillándolos en una dialéctica inhumana de guerra, sentenciados a un rechazo perpetuo para ejercer los liderazgos. Es esencial que si se espera una futura generación más participativa no se relacione la política opositora con el terrorismo, violencia o resiliencia.

El campo de estudio del presente resultado de investigación no fue el de juzgar la gravedad de los actos en épocas de violencia, es el de resaltar la posibilidad real de avanzar y dar una continuación a la lucha, esta vez, desde espacios directos a la legalización.

\section{Referencias}

Acuerdo Final para la Terminación del Conflicto y la Construcción de una Paz Estable y Duradera. (2016). Colombia.

https://www.jep.gov.co/Documents/Acuerdo\%20Final/Acuerdo\%20Final\%20Firmado.pdf

Anderson, J. (2016). Es muy peligroso que la sociedad no reciba a las Farc. El Tiempo.

Columna Web. https://www.eltiempo.com/politica/proceso-de-paz/efectos-de-norecibir-en-la-sociedad-a-las-farc-41448

Arendt, H. (1958). La Condición Humana. Ediciones Paidós

Anto, R. (2018). El mecanismo de espiral del silencio (Noelle-Neumann). Política y medios. Net. https://politicaymedios.net/espiral-del-silencio/

Arias, R. (2015). El proceso de paz. Los retos para la sociedad colombiana. Sextante. https://sextante.uniandes.edu.co/index.php/ejemplares/sextante-5/latitudes/el-procesode-paz 
Basset, Y. (2018). Claves del rechazo del plebiscito para la paz en Colombia. Estudios Políticos. Francia http://www.scielo.org.co/pdf/espo/n52/0121-5167-espo-52-00241.pdf

Boris, M. (2016). Las razones por las que el "No" se impuso en el plebiscito en Colombia. BBC News. Artículo Web.

https://www.bbc.com/mundo/noticias-america-latina-37537629

Caro, A. (2020). Proteger la vida de líderes, lideresas sociales y excombatientes y construir territorios de paz. Revista Sur. https://www.sur.org.co/proteger-la-vida-de-lidereslideresas-sociales-y-excombatientes-y-construir-territorios-de-paz/

Comisión de Personalidades. (2017). Recomendación de la mesa de diálogos. Idepaz. http://www.indepaz.org.co/documento-de-recomendaciones-de-la-comision-depersonalidades/

Córdoba, K. y Vela, M. (2017). La participación política de excombatientes de las FARC-EP en el proceso de justicia transicional en Colombia. Universidad Javeriana http://vitela.javerianacali.edu.co/handle/11522/8236

Corte Constitucional. Sentencia C- 571- 2019 https://www.corteconstitucional.gov.co/relatoria/2019/C-571-19.htm

Fisas, V. (2010). Introducción a los procesos de paz. Barcelona: Escola de Cultura de Pau. https://escolapau.uab.cat/img/qcp/introduccion_procesos_paz.pdf

Forst, R. (2014). Justification and Critique. Towards a Critical Theory of Politics. Polity Press. Cambridge.

Hobsbawn, E. (2015). iQué viva la Revolución!. Edición Crítica.

Jaramillo, S. (14 de enero de 2018). La inclusión política garantiza que no se repita la violencia. El Tiempo. https://www.eltiempo.com/politica/proceso-de-paz/la-inclusionpolitica-de-las-farc-garantiza-que-no-se-repita-la-violencia-en-colombia-170726

John, R. y Raven, B. (1992). "A power interaction model of interpersonal influence: French and Raven thirty years later". Journal of Social Behavior and Personality.

Línea Conflicto, Paz y Postconflicto-Pares. (2019). Procesos de paz en Colombia. Fundación Paz y Reconciliación. https://pares.com.co/2019/01/04/procesos-de-paz-encolombia/ 
Madrigal, L. (2010). Relación amigo-enemigo ¿Homogeneización del otro? Revista Kavilando, https://www.kavilando.org/revista/index.php/kavilando/article/view/314

Martines, M. (2006). Pactos de élites y transición a la democracia en Venezuela y Colombia. Politeia. Caracas Venezuela. https://www.redalyc.org/pdf/1700/170018238008.pdf

Méndez, N. y Casas, A. (2009). Educación para la paz, cultura política y cambio social: un análisis empírico del programa Aulas en Paz desde el institucionalismo cognitivo. Desafíos, 21, 97-134. https://revistas.urosario.edu.co/index.php/desafios/article/ view/448

Miranda, B. (2016). Las razones por las que el "No" se impuso en el plebiscito en Colombia. Nota BBC. https://www.bbc.com/mundo/noticias-america-latina-37537629

Misión Verificación ONU. S / 2020 / 943. https://reliefweb.int/sites/reliefweb.int/files/resources/Misi\%C3\%B3n\%20de\%20Verificaci\%C3\%B3n\%20de\%20las\%20Naciones\%20 Unidas\%20en\%20Colombia\%20-\%20Informe\%20del\%20Secretario\%20General\%20 \%28S-2020-943\%29.pdf

Monzón, C. (2006). Opinión pública, comunicación y política. España: Tecnos.

Neumann, E. (1995). La espiral del silencio. Opinión pública: nuestra piel social. Paidós. Barcelona.

https://www.infoamerica.org/documentos_pdf/noelle_neumann.pdf

Participación política y conflicto armado. (12 de julio de 2013). El Espectador.

https://www.elespectador.com/opinion/participacion-politica-y-conflicto- armadocolumna-433430/

Pécaut, D. (2015). Un conflicto armado al servicio del status quo social y político. En Comisión histórica del conflicto y sus víctimas (Ed.), Contribución al entendimiento del conflicto armado en Colombia. http://www.humanas.unal.edu.co/observapazyconflicto/files/5714/6911/9376/Version_final_informes_CHCV.pdf

Redacción el Tiempo. (2016). Diferencia entre el 'No' y el 'Sí' muestra la división que existe en el país en torno a la paz. El Tiempo. Artículo Web.

https://www.eltiempo.com/politica/proceso-de-paz/resultados-plebiscito-2016-42861

Rueda, E. (2015). Cultura política para forjar la paz en Colombia. Buenos Aires: CLACSO: http://biblioteca.clacso.edu.ar/clacso/becas/20150318010520/Culturapolitica.pdf 
Sartori, G. (2020). El concepto de democracia. Dígalo ahí Digital. https://digaloahidigital. com/articulo/giovanni-sartori-y-el-concepto-de-democracia

Sartori, G. (2012). ¿Qué es la democracia? Madrid: Taurus.

Saumeth, E. (2010). Historia de la guerrilla en Colombia. http://www.ecsbdefesa.com.br/ defesa/fts/HGC.pdf

Turriago, D. (2016). Los procesos de paz en Colombia, camino ¿a la reconciliación? Actualidades Pedagógicas, (68). Recuperado de: https://doi.org/10.19052/ap.3827

Uraguiza, J, (2013). La dimensión política del postconflicto: discusiones conceptuales y avances empíricos. Colombia Internacional, 77, 141-176. http://www.scielo.org.co/ $\mathrm{pdf} / \mathrm{rci} / \mathrm{n} 77 / \mathrm{n} 77 \mathrm{a} 06 . \mathrm{pdf}$

UNESCO. (1945). Constitución UNESCO. Preámbulo.

Verdú, 0. (2017). Crisis, libertad y representación política en el pensamiento de Hannah Arendt: aplicación al análisis del movimiento 15-M como respuesta a la crisis económica en el estado español [Tesis doctoral, Universidad Complutense de Madrid]. Archivo digital. https://eprints.ucm.es/id/eprint/43327/1/T38927.pdf

Vergara, J. Prada, T. Aparicio, A. y Martínez, L. (2019). ¿Cómo están las condiciones de seguridad de los excombatientes de las FARC? Fundación Ideas para la Paz. http:// www.ideaspaz.org/publications/posts/1771 